\title{
TRABALHO DOCENTE EM PERSPECTIVA SÓCIO-HISTÓRICA: A POSIÇÃO DE CLASSE DO PROFESSOR E OS DESAFIOS CONTEMPORÂNEOS
}

\author{
Ivonaldo Leite ${ }^{1}$ \\ Universidade Federal da Paraíba (UFPB)
}

\begin{abstract}
RESUMO
O artigo tem como objetivo apresentar a posição de classe do professorado e, ao mesmo tempo, descrever alguns dos desafios que a reestruturação capitalista tem colocado ao trabalho docente. Para tanto, metodologicamente, faz-se uma revisão da literatura científica da área, bem como de documentos de organizações internacionais que têm procurado influenciar os rumos da educação em diferentes países. Dentre os seus resultados, o artigo demonstra que: 1) o professor é um trabalhador intelectual cujas atividades estão sendo extremamente proletarizadas atualmente; 2) a reestruturação capitalista tem redefinido a relação entre trabalho e educação; 3) como alternativa contra-hegemônica, evidencia-se a necessidade de o trabalho docente ser desenvolvido realizando uma conexão entre novas tecnologias e ética, partindo, no cotidiano escolar, da categoria práxis como categoria englobante do ser social.

Palavras-chave: Educação, professor, classe social, trabalho, reestruturação capitalista.
\end{abstract}

\section{TEACHING WORK IN A SOCIOHISTORICAL PERSPECTIVE: TEACHERS' SOCIAL CLASS AND CONTEMPORARY CHALLENGES}

\begin{abstract}
This paper has as objective to define the social class of the teachers and, at the same time, to describe some challenges that the capitalist restructuring has addressed for them. In this sense, methodologically, it makes a revision of the scientific bibliography in that academic field, as well as of some internationals organizations' documents that have tried to influence the educational policies in different countries. The paper got, for example, the following outcomes: 1) a teacher is an intellectual worker, and actually he is under an intense process of proletarization; 2) the capitalist restructuring has redefined the relationship between work and education; 3) as a counter-hegemonic alternative, it's necessary that the teachers develop their work making a connection with the new technologies and an ethical perspective, and also paying attention to praxis concept in school everyday life, as concept which reflects the social being in his totality.

Keywords: Education, teacher, social class, work, capitalist restructuring.
\end{abstract}

\section{A posição de classe do professor}

A singularidade que caracteriza o trabalho docente requer, do ponto de vista sindical - no que se refere à definição da posição de classe do professor -, que se estabeleça uma conexão com os setores intermediários das classes, onde é de se notar designadamente a presença de frações pequenas burguesas.

Historicamente, de modo geral, tais segmentos - embora não só eles - têm dado corpo ao trabalho docente, isto é, deles são oriundos os profissionais do ensino. Como 
decorrência desse fato, emerge uma questão central: Pode o professor ser considerado um trabalhador? A propósito, numa demonstração do que, sociologicamente, caracteriza as oscilações desses segmentos, um estudo que se tornou clássico, realizado em França, mostra como os mesmos ora tendem a assumir posições progressistas, principalmente no contexto do serviço público, ora tendem a encampar posições conservadoras, principalmente no âmbito da vida privada (Boltanski, 1982).

Faz-se necessário, contudo, ter em consideração as classes numa perspectiva mais aprofundada. Em sentido amplo, trata-se de um tema controverso, mesmo no interior da teoria social marxista, que se notabiliza pelo realce que atribui ao assunto. Em $O$ Capital, como se sabe, Marx foca a temática das classes em poucas linhas, que ficam interrompidas. Entretanto, é, sobretudo, em obras como o Dezoito Brumário de Luís Bonaparte que ele se debruça sobre a questão de forma mais sistematizada, e aporta bases para, penso eu, se evitar abordagens eivadas pelo reducionismo do determinismo econômico. A propósito, há uma passagem na referida obra, no tocante aos camponeses, que é paradigmática a este respeito. Afirma Marx (1974, p. 115-116):

Na medida em que milhões de famílias camponesas vivem em condições econômicas que as separam umas das outras, e opõem o seu modo de vida, os seus interesses e sua cultura aos das outras classes da sociedade, estes milhões constituem uma classe. Mas na medida em que existe entre os pequenos camponeses apenas uma ligação local e em que a similitude de seus interesses não cria entre eles comunidade alguma, ligação nacional alguma, nem organização política, nessa exata medida não constituem uma classe. São, consequentemente, incapazes de fazer valer seu interesse de classe em seu próprio nome, quer através de um parlamento, quer através de uma convenção.

Mutatis mutandis, o que se infere de passagens como esta (e de outras de $O$ Dezoito Brumario) é que apenas o lugar no processo de produção não é suficiente para gerar identidades e diferenciar setores sociais no que se refere às dimensões políticas, ideológicas e culturais, embora o mencionado lugar possa ser referido como 'ultima instância' de condicionamento. Ou seja, a infraestrura não determina automática $e$ mecanicamente a pertença de classe, erguendo, como reflexo direto, o edifício da superestrutura social. Aliás, a este respeito, Engels, cinco anos antes do seu falecimento, não poderia ser mais elucidativo. Peço vênia pela extensão da citação, mas sendo ela substancial para a perspectiva aqui seguida, coloco em evidência o que afirmou Engels em 1890:

Segundo a concepção materialista da história, o fator que, em última instância, determina a história é a produção e reprodução da vida real. Nem Marx nem eu afirmamos, uma vez sequer, algo mais do que isso. Se alguém o modifica, afirmando que o fator econômico é o único fator determinante, converte aquela tese numa frase vazia, abstrata e absurda. A situação econômica é a base, mas os diferentes fatores da superestrutura que se levantam sobre ela - as formas políticas da luta de classes e seus resultados, as constituições que, uma vez vencida uma batalha, a classe dominante redige, etc., as formas jurídicas, e inclusive os reflexos de todas essas lutas no cérebro dos que nelas participam, as teorias políticas, jurídicas, filosóficas, as ideias religiosas e o desenvolvimento ulterior que as leva a converter-se num sistema de dogmas - também exercem sua influência sobre o curso das lutas históricas e, em muitos casos, determinam sua forma como fator 
predominante. Trata-se de um jogo recíproco de ações e reações entre todos esses fatores, no qual, através de toda uma infinita multidão de acasos (isto é, de coisas e acontecimentos cuja conexão interna é tão remota ou tão difícil de demonstrar que podemos considerá-la inexistente ou subestimá-la), acaba sempre por impor-se, como necessidade, o movimento econômico. Se não fosse assim, a aplicação da teoria a uma época histórica qualquer seria mais fácil que resolver uma simples equação de primeiro grau (Engels, 1986, p. 28).

Ou seja, impõe-se como imprescindível adotar uma concepção dialética das classes, considerando as (sobre)determinações que atuam em níveis distintos (mas entrelaçados), como o modo de produção em âmbito mais abstrato, as formações sociais em um âmbito mais concreto e o modo de vida, numa esfera mais específica. Importa, portanto, como assinalou Poulantzas (1977), que se tenha em conta a relação entre formações sociais e modos de produção.

O que está em causa, fundamentalmente, é que se adote como premissa que a teoria social marxista não elabora categorias gerais (o econômico em geral, o político em geral, as classes em geral, etc.). Dessa forma, não há o espectro do economicismo a rondar a compreensão das classes como categorias economicamente determinadas. Repisando o básico: como conceito, as classes referem-se a situações nas quais a distribuição social das pessoas, tendo como referência a organização da produção, é, por certo, o critério central para a estruturação das camadas da população; porém, isso não é algo que se basta a si, na medida em que é necessário considerar o condicionamento de duas outras instâncias: a política e a ideologia. O condicionamento não ocorre a partir das instâncias isoladas, mas como um "feixe", decorrente da tripla articulação entre elas (economia, política e ideologia), pelo que, assim sendo, as classes não podem ser niveladas às categorias gerais que a teoria social marxista põe de parte.

A conceituação das classes sociais consubstancia um corpo categorial que indica os efeitos do conjunto das estruturas, da matriz de um modo de produção, ou de uma formação social, sobre os agentes que constituem o seu todo. Indica, assim, os efeitos da estrutura global no domínio das relações sociais. Enfim, cabe sempre (re)lembrar que a constituição, e portanto a própria definição das classes, das frações, das camadas e das categorias, não pode ser feita senão tomando-se em consideração o fator dinâmico das classes e grupos em luta, pois a delimitação da estrutura classista não se reduz apenas a uma espécie de descrição estática das estatísticas. Ela depende do movimento do processo histórico.

Partindo do background aqui posto em evidência, e ao se observar a configuração empírica do trabalho docente nos dias atuais, é de se destacar um conjunto de aspectos com significativa relevância para propósitos analíticos.

Numa época de crise, como a que vive o capitalismo nos últimos tempos, onde os impasses relativos à acumulação e os déficits de legitimação são dois dos elementos a serem destacados, a tendência é de se aprofundar a proletarização do trabalho e se intensificar os seus mecanismos de gestão, no sentido de extrair o máximo possível de produtividade. É a clássica lógica operacional da obtenção de mais-valia dando as cartas. O contexto educativo não está imune a esse quadro; pelo contrário, cada vez mais, por exemplo, são adotados nas escolas os mecanismos de gestão tipicamente oriundos da esfera da produção material, bem como, de forma ascendente, o modo como são definidos os procedimentos administrativos para tratar da profissão docente são tipicamente fabris.

Como decorrência disso, os professores têm estado envolvidos numa ampla e cada vez maior reestruturação das suas funções, na qual consta: a) a imposição constante de 
procedimentos de controle técnico no currículo das escolas, onde se tem uma integração instrumental de sistemas administrativos; b) currículos redutores de orientação comportamental; c) "competências" de ensino predeterminadas de forma inteiramente exógena; d) respostas dos alunos igualmente predeterminadas, com mecânicas avaliações prévias e posteriores (tanto as avaliações da aprendizagem como as chamadas avaliações institucionais).

Pode-se afirmar, portanto, que a escola tem sido um locus que ocupa cada vez mais pessoas, e em maior tempo, como instância necessária ao sistema para a realização da mais-valia. Nesse sentido, a atividade que ela abriga define-se como um trabalho sintonizado com a mesma lógica do trabalho produtivo da esfera econômico-material. Isto é, a atividade docente assume a padronização e a segmentação como características centrais.

Nesse sentido, cabe razão a João Bernardo, quando ele assinala que, sem tais características, o sistema não pode equiparar sob a mesma rubrica quantitativa trabalhos que, qualitativamente, são diferentes. De fato, a padronização e a segmentação são requisitos determinantes para transformar o exercício de qualquer profissão em dispêndio de tempo de trabalho. Por ser desse modo, os docentes perderam o controle não só sobre a matéria que lecionam, mas principalmente sobre o seu próprio tempo de trabalho.

Todavia, o produto da ação do professor tem, relativamente a todos os outros, uma especificidade: ser produtor. "Assim, aquilo que em termos de input constitui tempo de trabalho aparece, em termos de output, como qualificações" (Bernardo, 1998, p. 34). Numa terminologia sugestiva, tem-se então que o aluno é um "trabalhador-input, porque está a receber inputs de tempo de trabalho resultantes da atividade dos professores e dos demais agentes de ensino. Finalizado o tempo da sua formação, o trabalhador-input transforma-se em trabalhador-output, capaz de converter as suas qualificações em dispêndio de outputs de tempo de trabalho. Nessa acepção, o processo escolar consiste na produção de trabalhadores-input (os alunos) graças aos trabalhadores-ouput" (ibidem, p. 35).

Posto isto, e considerando-se a discussão sobre a posição de classe do professor, revela-se extremamente pertinente conceituá-la a partir de uma perspectiva gramsciana, de par com a genealogia categórica trabalho intelectual e trabalho manual (Gramsci, 1978)2, para defini-lo como um trabalhador intelectual que é funcionário de um organismo da sociedade (a escola, a universidade), implicado na tarefa de socialização da cultura. Ou seja, o trabalho docente, transformando professor e aluno, afirma-se como uma ação intelectual, mas não se limita a isso, na medida em que, como demonstração da sua dimensão teórico-prática, só se efetiva se estiver relacionado com a realidade em que o ato pedagógico se desenvolve.

Quer dizer, a atividade docente pressupõe que o professor, como trabalhador intelectual, "desenvolva um trabalho prático de transformação estrutural da organização escolar, que se integra na transformação mais ampla da sociedade da qual ele participa, tanto mediante sua ação, como cidadão, como pela educação da consciência que a ação pedagógica produz" (Ribeiro, 1984, p. 51-52).

Mesmo que, em princípio, os professores apareçam como situados numa posição social contraditória, do ponto de vista da sua pertença de classe, a verdade é que a forma como o seu trabalho está delineado pela estrutura sistêmica, sobretudo atualmente, faz com que a tendência a sua proletarização se acentue.

Possivelmente, dentre outras, possa-se invocar duas objeções à abordagem sobre a posição de classe do professor que aqui realço: uma oriunda do esquerdismo (a velha doença infantil...) e outra advinda de uma perspectiva liberal ou do liberalismo socialdemocrata. Neste segundo caso, o que, por certo, colocar-se-á em relevo é o conceito de 
categoria social, conforme a tradição teórica que, no limite, remonta a sua filiação à formulação de Karl Mannheim sobre a chamada intelligentsia "livremente flutuante", ou seja, os intelectuais (na situação em foco, os professores), como grupo "autônomo", estariam acima de condicionamentos sociais (Mannhein, 1986).

Ora, neste último caso, como bem assinalou Lukács (2003), de resto repetido de forma recriada por Goldman (1986), todo conhecimento da sociedade está estreitamente relacionado com a estrutura social onde ele é produzido, no sentido de que os seus produtores estão ligados à consciência de uma determinada classe ou grupo. Isto não significa, claro está, que inexista um espaço de autonomia relativa para a elaboração científica, mas que, como bem ressaltou Goldmann, o cientista, aquele que se encontra empenhado no trabalho intelectual (como o professor, assinalo eu), é um indivíduo com relações de classe. Portanto, a ideia de intelligentsia "livremente flutuante", de trabalho intelectual livre de influência ideológica, não tem sustentação lógica nem empírica.

No que concerne à objeção que recusa a posição de classe do professor, aqui delineada sob o argumento de que ele não ocupa um lugar no processo de produção material, ela tem uma forte inconsistência teórica. Qual seja, ignora as configurações do capitalismo contemporâneo, onde a funcionalidade da estrutura escolar/de formação profissional, como pusemos em evidência, torna-se cada vez mais orgânica à sobrevivência e reprodução do sistema. Dessa maneira, tal postura provavelmente também ignora que as novas formas de organização do trabalho repõem sob novas bases as leis de circulação da mercadoria.

\section{Metamorfoses contemporâneas do capital na educação: desafios aos professores}

Contemporaneamente, a intensificação da proletarização do trabalho docente ocorre de par como uma série de metamorfoses do capital no contexto educativo em geral. São metamorfoses que, ao mesmo tempo, regulam o trabalho dos professores, buscam (re)definir projetos educativos e instituir um novo conjunto de expressões linguísticas para teleguiar a prática dos profissionais da educação.

Nesse sentido, várias iniciativas têm procurado estabelecer as bases nas quais devem ser desenvolvidas as políticas de educação e formação, em função do emprego ${ }^{3}$, constituindo um todo que, mesmo que às vezes não seja inteiramente normativoinstrumental, tem como marca distintiva a funcionalidade sistêmica, principalmente quando assume a perspectiva de macro-orientação para os diversos países. Como componentes de uma amostra desse todo, pode nomear-se, por exemplo: OCDE (1987; 1989), Banco Mundial (1995; 1999), UNESCO (1989; 1996), CEPAL (1990; 1995), CEPAL \& UNESCO (1992) Comissão Europeia (1994; 1995). Nos textos destas organizações, categorias como empregabilidade, competências e flexibilidade desempenham um destacado papel.

Há uma linha de conexão entre algumas dessas categorias, sendo uma referência disso a que se estabelece entre empregabilidade e competências, posto que esta última, em sua origem, está associada à crise da noção de posto de trabalho e à de um determinado modelo de classificação das relações profissionais. Ou seja, isto significa que a correspondência entre um saber, uma responsabilidade e uma carreira tende a se desfazer, na medida em que as relações de trabalho se modificam. Às exigências do posto de trabalho, sucede-se um estado instável de distribuição de tarefas, onde a colaboração, o empenhamento e a mobilidade passam a ser "qualidades" dominantes. Por sua vez, a empregabilidade consubstancia-se como a capacidade do trabalhador não só obter um emprego, mas, também, de se manter num mercado em mutação, de onde decorre uma 
transferência de responsabilidades para ele próprio pela sua não contratação ou demissão, como resultado de não estar formado para o emprego - não se encontrar "empregável" -, não tendo as competências exigidas pelo mercado, o que o remete para um universo de incompetência.

Nesse cenário, a qualidade da educação é mensurada pela sua eficiência nas estratégias voltadas para o desenvolvimento econômico e, para tal, deve formar uma mãode-obra polivalente, apta a lidar com a flexibilidade dos novos processos de trabalho e competente para se adaptar aos imprevistos do mercado. Com uma outra construção retórica, mas não completamente nova, regressa-se à Teoria do Capital Humano, como ocorre, por exemplo, nas formulações da CEPAL/UNESCO para a América Latina ${ }^{4}$ (CEPAL \& UNESCO, 1992). O que levou Coragio (1993, p. 3) a afirmar, numa abordagem sobre economia e educação, que: "discutir o sentido do rejuvenescimento da Teoria do Capital Humano é uma tarefa teórica que deve ser empreendida, se se quiser ter uma maior compreensão do processo de recomposição da economia mundial."

O referido documento da CEPAL/UNESCO apresenta a combinação produção/acumulação de conhecimento como sendo força motriz do desenvolvimento, postulando uma Nova Economia da Educação (Paiva \& Warde, 1993). Tal "força" outra coisa não é que a ideia-chave da Teoria do Capital Humano: A compreensão segundo a qual um acréscimo de educação - ou, mais concretamente, instrução/treinamento -, corresponde um acréscimo da capacidade de produção (Schultz, 1962; 1973).

É assim que a relação entre educação e mercado de trabalho nas sociedades contemporâneas é apresentada como algo indispensável (OCDE, 1989), com o ensino devendo "desenvolver as diversas competências que as economias exigem" (ibidem, p. 85). Sublinhando-se que se vive numa sociedade cognitiva, à educação é atribuída uma função fundamental no relançamento da competitividade e do crescimento, responsabilizando-se o indivíduo pela sua própria formação profissional/assimilação das competências demandadas pelo mercado (Comissão Europeia, 1994; 1995). Isto é, a educação e a formação são "chamadas a desempenhar um papel determinante" (Comissão Europeia, 1994, p. 139). A propósito dos documentos da Comissão Europeia, Afonso e Antunes (2001, p. 4), ao analisá-los, constatam que:

(...) Reiterações da importância da educação e da formação para a resolução dos problemas da competitividade e, sobretudo, do emprego, sobrepõem-se a todos os outros fatores em jogo (...). Assim, na enumeração dos fatores que supostamente podem contribuir para a melhor solução dos problemas criados pelas mutações econômicas em curso, as políticas do Estado e das instituições europeias e a ação dos agentes econômicos parecem menos decisivas do que a ação dos sistemas educativos (...).

Na sequência da análise, e como decorrência do que constatam, afirmam que:

Em termos de discursos oficiais e de orientações vindas de instâncias comunitárias (UE), ao sobrevalorizar-se nomeadamente o pressuposto de que a aprendizagem que conta é aquela que se guia pela maximização da sua utilidade econômica imediata, utilidade esta justificada em termos de uma racionalidade idêntica a da teoria do capital humano, a ideia da sociedade da aprendizagem acaba por ser fortemente instrumental e redutora, ainda que seja possível, a partir da sua problematização, verificar que pode cumprir outras funções latentes mais amplas (ibidem, p. 4-5). 
As organizações mencionadas, contudo, salientam que os sistemas educativos não estão preparados para desempenhar o papel que lhes é atribuído, pois, entre as suas limitações, aponta-se, por exemplo, a desadequação entre a formação que eles oferecem aos alunos e as exigências dos sistemas produtivos/tecnológicos cada vez mais complexos e sujeitos a fortes mudanças/mutações (UNESCO, 1989). Ou seja, quer isto significar que os sistemas educativos devem reproduzir as condições socialmente diferenciadas, pelo que se afasta, portanto, do ideário de escola unificada (OCDE, 1989). É o horizonte apontado para as reformas educativas, incentivando o incremento do ensino técnico e profissional.

São definidas como diretrizes reformistas, entre outras, a necessidade de despertar nos alunos a capacidade para eles trabalharem em grupo; o incentivo para que os métodos/instrumentos pedagógicos nas escolas se assemelhem aos existentes no mercado de trabalho; o estabelecimento de relações com as empresas, etc. (OCDE, 1987). Por seu turno, as empresas devem tomar como pressuposto o entendimento de que as transformações introduzidas pelas novas tecnologias ocasionam a descentralização da tomada de decisões, tornando-se acessíveis ao meio envolvente, com o qual repartem responsabilidades e recebem indicações à (re)formulação dos seus objectivos e regras gerais. Deve-se ainda, no caso dos sistemas de ensino-formação, diluir as responsabilidades por um conjunto de intervenientes sociais, particularmente os centrados na escola e os associados ao meio empresarial (ibidem). Pela dinâmica deste processo, acentua-se, os sistemas de ensino-formação devem se transformar em centros de formação, não apenas de formação de base, mas também de formação continuada.

Mas, além de se defender o incremento do ensino técnico e profissional para atender "às novas exigências", a implementação do mesmo também é valorizada como mecanismo para combater o insucesso escolar e como forma de normalizar o acesso ao ensino superior.

No primeiro caso, a ideia central é que, na escola, há alunos - nomeadamente originários das classes populares - que, entende-se, por "não terem capacidade de abstração", "fracassam" e a abandonam, pois são portadores de códigos linguísticos e de saberes práticos insuficientes ao o que nela se passa, tendo uma definição de futuro limitada (Martins, 1999). Assim, segundo esta compreensão, o ensino técnico e profissional apresenta potencialidades na resolução do insucesso escolar, fato que se deve quer "à natureza dos seus objetivos, que privilegiam a entrada direta no sistema de emprego através de caminhos mais curtos que o ensino superior, quer, e sobretudo, devido à natureza dos seus currículos, já que apresentam uma forte componente prática" (Martins, 1999, p. 114). Tais elementos, conjugados, estariam mais de acordo com as condições dos alunos provenientes das classes populares, o que promoveria uma articulação benéfica para a sociedade: da formação com as necessidades do mercado de trabalho, com as condições objetivas dos alunos e, provavelmente, sustenta-se, com as suas próprias aspirações. Em síntese:

O ensino técnico e profissional assume-se com capacidade para intervir na resolução do insucesso escolar massivo, evitando por esta forma que os alunos abandonem a escola e a formação e que, ao não serem absorvidos pelo sistema de emprego, formem grupos de marginais [o grifo é nosso] e de difícil integração social (ibidem, p. 114).

No que se refere ao segundo caso (normalizar o acesso ao ensino superior), partese da seguinte compreensão: $\mathrm{O}$ ensino de massas conduziu os alunos até à universidade, alargando a sua frequência para lá dos limites que as estruturas universitárias suportam, criando graves problemas para o sistema educacional, dado que a universidade "não 
comporta a entrada de todos". A partir deste entendimento, incorpora-se o ensino técnico e profissional na resolução da questão:

A resolução deste problema pode ser feita recorrendo-se a dois processos,
de alguma forma complementares. Num primeiro, criam-se impedimentos
objetivos. Neste caso, limita-se o número de entradas, variando-se apenas
os processos pelos quais é feita a seleção. No segundo caso, a limitação
obtém-se através da normalização do sistema educativo, consistindo esta
em criar uma multiplicidade de saídas, o que vai contrariar o
afunilamento cujo fim fica à beira da universidade. Nesta perspectiva, os
ensinos profissional e técnico-profissional apresentam uma grande
funcionalidade na resolução dos problemas que perturbam o sistema
educativo" (ibidem, p. 115).

No percurso do posicionamento em apreço, também se tem abordado a relação entre saberes gerais, científicos e profissionais, donde decorre a discussão sobre em que instância a formação profissional deve começar/ser desenvolvida.

$\mathrm{Na}$ defesa de uma formação que torne o indivíduo empregável, dotado com as competências demandadas pelo mercado, tem-se recomendado atenção à flexibilidade, pois "as tendências que hoje se verificam nas dinâmicas econômicas evidenciam que os sistemas de formação, em geral, e as estruturas curriculares, em particular, não respondem às necessidades criadas" (Martins, 1999, p. 137), posto que tais sistemas "se estruturaram segundo as lógicas tayloristas-fordistas, [onde] os indivíduos eram formados para a ocupação de lugares especializados ou para lidarem com um conjunto restrito de técnicas, de forma bastante dicotômica e com interação fraca (...)" (ibidem, p. 137). Daqui decorrem algumas divergências no interior da perspectiva da empregabilidade e das competências.

Há duas visões sobre o rumo da formação profissional: Por um lado, há quem defenda que a mesma, diante das reconfigurações verificadas, deve priorizar os saberes gerais/científicos, tendo na escola regular um espaço formativo fundamental; e, por outro lado, existem os defensores dos sistemas específicos de formação, com acento na componente profissionalizante.

Esta última posição, nem sempre defendida explicitamente, é algo mais típico do patronato:

No caso dos empregadores, existem restrições na escolha e aplicação de estruturas curriculares equilibradas pela defesa que fazem de uma componente profissionalizante forte, que permita aos formandos a aquisição de saberes técnicos no domínio de uma técnica ou de um conjunto restrito de técnicas, que os tornem aptos a integrarem-se no sistema produtivo sem gastos de aprendizagem e, por conseguinte, serem produtivos de imediato (ibidem, p. 135).

Este posicionamento tem sido criticado por, não considerando a mutabilidade introduzida pela novas tecnologias, ter uma compreensão imediatista do processo de produção e da mão-de-obra selecionada, desprezando uma avaliação estratégica no âmbito da economia global, sendo, por isso, os seus defensores qualificados como ultrapassados e sem maleabilidade intelectual para perceberem os novos saberes e comportamentos necessários (Lopes, 1992).

Em contraposição, é feita a defesa do ensino geral, fornecedor de uma base ampla de conhecimentos, a partir da qual, posteriormente, acrescentar-se-iam elementos profissionalizantes específicos. Trata-se da defesa da ideia que parte da pressuposição de 
que a escola regular transformou-se num espaço imprescindível à formação profissional. A este respeito, o Relatório da Comissão Internacional sobre a Educação para o Século XXI, criada pela UNESCO em 1993, e publicado sob o título de Educação: Um Tesouro a Descobrir, é extremamente paradigmático. Nele, encontra-se o entendimento segundo o qual se deve formar, antes de tudo, generalistas, observando-se que é indispensável uma base de conhecimentos gerais para os futuros trabalhadores poderem dominar as mudanças tecnológicas tão rápidas quanto imprevisíveis - a educação, portanto, deve dar aos indivíduos a flexibilidade necessária para que se adaptem às mudanças, como o desenvolvimento do trabalho a tempo parcial e/ou a domicílio (UNESCO, 1996).

Outra também não é a proposição de Guiomar Namo de Mello, num trabalho sistematizado, por exemplo, a partir de intervenções suas em eventos como o realizado pela UNESCO em Santiago do Chile, em 1992:

A educação é hoje uma prioridade revisitada no mundo inteiro. Diferentes países, de acordo com suas características históricas, promovem reformas em seus sistemas educacionais, com a finalidade de torná-los mais eficientes, (...) capazes de enfrentar a revolução tecnológica que está ocorrendo no processo produtivo. O conhecimento, a capacidade de processar e selecionar informações, a criatividade e a iniciativa, constituem matérias-primas vitais para o desenvolvimento. Os países industrializados mais adiantados deslocam, assim, as prioridades de investimento em infra-estrutura e equipamentos, para a formação de habilidades cognitivas e competências sociais da população. Esse deslocamento faz com que a educação escolar adquira centralidade nas pautas governamentais e na agenda dos debates que buscam caminhos para uma reestruturação competitiva da economia" (Namo de Mello, 1998, p. 30).

Colocada entre dois cenários, a formação para o emprego termina por ser mais sublinhada na dimensão que concebe a escola regular como espaço prioritário para o desenvolvimento dos requisitos profissionalizantes, sob o impulso das formulações em torno das noções de empregabilidade e competências. Estas, todavia, operam numa lógica cujos princípios não são revelados quando elas são ditas.

Mais do que pensar a inclusão dos trabalhadores no mercado, o que está subjacente à empregabilidade, por exemplo, é a premissa de que as políticas educacionais/de formação devem orientar-se "para garantir a transmissão diferenciada de competências flexíveis que habilitem os indivíduos a lutarem nos exigentes mercados laborais pelos poucos empregos disponíveis" (Gentili, 1998, p. 89). Isto não se passa sem consequências mais amplas no plano da sociabilidade: "A garantia do emprego como direito social (e sua defesa como requisito para as bases de uma economia e uma vida política estável) desmanchou-se diante da nova promessa de empregabilidade" (ibidem, $\mathrm{p}$. 89). A escola, local onde devem ser buscadas as competências, torna-se esvaziada de funções sociais, com a produtividade institucional sendo reconhecida nas habilidades que os seus alunos-clientes possam vir a dispor para responder aos desafios que um mercado altamente seletivo impõe.

Por outro lado, a ascensão da noção de competências vincula-se estreitamente à erosão do padrão fordista de acumulação, pois, sendo a qualificação um dos pontos capitais do "compromisso fordista", "cedeu-se a tentação de substituí-la pela competência como base de um novo modo de gestão acompanhando a transformação da organização do trabalho e a mudança na relação de formas entre patrões e sindicatos de assalariados (declínio acentuado da sindicalização e das negociações coletivas)" (Dubbar, 1998, p. 97). 


\section{À guisa de conclusão}

Procurei, neste trabalho, em princípio, discutir a posição de classe do professor, visitando a teoria social clássica, para defini-lo como um trabalhador intelectual que é funcionário de um organismo da sociedade (a escola, a universidade) implicado na tarefa de socialização da cultura. Em seguida, passei em revista as metamorfoses contemporâneas do capital na educação, perspectiva a partir da qual se podem visualizar os desafios que estão postos aos docentes nos dias atuais. Em forma de conclusão, agora, realço a necessidade de, para enfrentar estes desafios, a atividade docente assumir como pressuposto a realização de uma conexão entre trabalho, ética e novas tecnologias, partindo, no cotidiano escolar, da categoria práxis como categoria englobante do ser social.

Isto é, por práxis exprimimos a experiência fundante da vida humana, a experiência de o ser humano ser entregue a si próprio. Não se trata apenas de uma experiência que serve de base para toda a vida teórica e prática do ser humano, mas de uma experiência que emerge no próprio processo de questionamento da vida. Em poucas palavras, a experiência originária é a experiência de uma interpretação ao constituir-se; ao conquistar-se como ser, portanto, o ser humano emerge nesta experiência fundante como contrário do ser simplesmente dado. Práxis significa, precisamente, a forma própria de um ente que cria o seu próprio ser a partir da sua realidade primeira - que constitui o ponto de partida deste processo -, em relação à qual a práxis significa uma tomada de posição e, neste sentido, efetivação de transcendência, o que caracteriza o ser humano enquanto ser humano (Oliveira, 1996).

Isto pressupõe a capacidade de projetar uma situação diferente, uma facticidade transcendente à facticidade originária, isto é, uma configuração alternativa à condição de origem. Quer dizer, se o ser humano é um ente da natureza como qualquer outro, o que o especifica é que ele se situa propriamente como humano, no para além da natureza, na esfera do por ele construído, através do que ele medeia seu próprio ser. Sendo as ações humanas e seus produtos mediação da gestação do ser humano enquanto ser humano, então "seu valor ético se decide pelo valor da pessoa humana que é sujeito e que se efetiva por sua mediação. Isto significa dizer que toda a atividade está, em última instância, a serviço da efetivação pessoal e que sua dignidade consiste, precisamente, em estar a serviço da vida humana" (ibidem, p. 189).

Se o homem é o ente da conquista de seu próprio ser, isto significa dizer que há a possibilidade de as suas atividades, ao invés de serem mediação de seu ser, poderem ser utilizadas como destruição deste ser, como opressão, como diminuição de sua dignidade, como sua violação, ou seja, elas podem ser transformadas em meio de alienação do próprio homem. Isto é, as ações humanas podem ser utilizadas como instrumento de degradação da pessoa humana na medida em que a dignidade do seu sujeito, das mais diferentes formas, não é efetivamente reconhecida. Aqui põe-se um elemento fundamental: A questão da ética da prioridade, ou seja, dos critérios racionais que devem determinar as ações enquanto ações humanas, a atividade humana enquanto atividade, em primeiro lugar, de um ente que, como carente, tem necessidades naturais a serem satisfeitas. Se o ser humano se experimenta a si mesmo como um ser a se construir, isto é, como ser histórico, ele se descobre como ser histórico, antes de tudo, como um ser vivo que produz $e$ reproduz, através de sua ação, seu próprio ser. Se, então, a história é o espaço da possível efetivação do homem como ser livre, ela o é, em primeiro lugar, como espaço da possível reprodução da vida. Isto significa que a razão de ser da ação econômica é, então, a 
satisfação, antes de mais nada, das necessidades básicas que reproduzem a vida humana, que não se reduzem às necessidades de sua reprodução material (ibidem).

Assim sendo, a "racionalidade" da ação econômica nunca é completa quando se considera apenas o seu aspecto sistêmico, ou seja, por exemplo, a eficiência na produção dos bens, mas implica fundamentalmente, em primeiro lugar, a configuração racional ética das relações sociais. Quer isto dizer que a ação econômica constitui um problema ético básico, isto é, o problema do conhecimento dos sujeitos em si como parceiros de igual dignidade e o problema do ser e do valor próprio da natureza, o que se consubstancia na construção de mecanismos institucionais que tornem este reconhecimento possível. O que significa mais: Pôr-se para além da racionalidade unidimensional em que se situou a economia política na modernidade e ainda se situa o pensamento econômico dos nossos dias, pois isto implica dizer que o problema da racionalidade econômica abrange duas dimensões de racionalidade: A racionalidade sistêmica e a racionalidade ética (ibidem).

$\mathrm{Na}$ primeira dimensão, o que está em jogo é o agir eficiente em relação aos recursos escassos. Racionalidade, nesta esfera, tem a ver com um controle eficiente de bens para satisfazer às necessidades humanas; na segunda, levanta-se a pergunta pelo sentido e pela contribuição da atividade em discussão para o processo de conquista da humanidade de homens e mulheres - o que se põe como questão primeira de sua racionalização é precisamente a configuração das interações sociais para saber se elas estão voltadas à reprodução da vida para todos.

Dessa forma, quando as novas tecnologias são concebidas como instrumentos meramente a serviço do aperfeiçoamento da reprodução econômica, atenta-se contra a dimensão ética, gerando uma lógica de desigualdade, "absolutizada quando o mercado é considerado o mecanismo exclusivo de coordenação de uma economia moderna, sem que nenhuma outra instância possa e deva determinar as metas sociais" (ibidem, p. 193).

Para que essa outra instância se constitua de forma ativa, é imprescindível o papel a ser desempenhado pelo professor, no sentido de, como foi assinalado no início deste artigo, realizar o trabalho teórico-prático que, situa-se na escola, mas insere-se também no contexto onde se desenvolve a ação pedagógica.

Nessa perspectiva, o trabalho docente, tendo em conta as reconfigurações societais contemporâneas, induzidas pelas novas tecnologias, ao trazer para o cotidiano escolar a reflexão sobre a questão ética, afirma-se conforme o seu estatuto originário, isto é, como ação que busca formar consciências para transformar a realidade.

\section{Referências}

AFONSO, Almerindo J. \& ANTUNES, Fátima. Educação, cidadania e competitividade: algumas questões em tono de uma nova agenda teórica e política. Braga, 2001 (mimeo).

BANCO MUNDIAL. Education sector strategy. Washington, D.C.: The World Bank Group. Human Development Network, 1999.

. Priorities and strategies for education. A World Bank Review. Washington, D.C.: The World Bank Group - Series Development in Practice, 1995.

BERNARDO, João. Estado: a silenciosa multiplicação do poder, São Paulo: Escrituras Editora, 1998.

BOLTANSKI, Luc. Les cadres: la formation d'un groupe social, Paris: Editions de Minuit, 1982.

CEPAL. Panorama social de América Latina. Santiago do Chile: CEPAL, 1995. 
.Transformación Productiva con Equidad. Santiago do Chile: CEPAL, 1990.

CEPAL \& UNESCO. Educación y conocimiento: eje de la transformación productiva con equidad. Santiago do Chile: Publicación de las Naciones Unidas, 1992.

COMISSÃO EUROPEIA. Ensinar e aprender: rumo à Sociedade Cognitiva (Livro Branco sobre Educação e Formação). Luxemburgo: Publicações Oficiais das Comunidades Europeias, 1995.

Crescimento, competitividade e emprego: os desafios e as pistas para educar no Século XXI (Livro Branco). Luxemburgo: Publicações Oficiais das Comunidades Europeias, 1994.

CORAGIO, J. L. Economía y educación en América Latina: notas para una agenda de los 90. S/L: CEAAL, 1993.

DUBBAR, Claude. A sociologia do trabalho frente à qualificação e à competência. In: Educação e Sociedade, nº 64, São Paulo, 1998.

GRAMSCI, António. Os intelectuais e a organização da cultura. Rio de Janeiro, Civilização Brasileira, 1978.

ENGELS, Friedrich. Carta a Bloch. In: MARX, Karl; ENGELS, Friedrich. Obras escolhidas. v. 3. São Paulo: Alfa-Ômega, 1986.

GENTILI, Pablo. Educar para o desemprego: a desintegração da promessa integradora. In: FRIGOTTO, Gaudêncio (Org.). Educação e crise do trabalho: perspectivas de final de século. Rio de Janeiro: Vozes, 1998.

LUKÁCS, George. História e consciência de classe: estudos sobre a dialética marxista. São Paulo: Martins Fontes, 2003.

GOLDMANN, Lucien, Filosofia e ciências humanas. São Paulo: Difel, 1986.

MANNHEIM, Karl. Ideologia e utopia. Rio de Janeiro: Guanabara, 1986.

MARX, Karl. O 18 Brumário de Luís Bonaparte e cartas a Kugelmann. 2 ed. Tradução: Leandro Konder. Rio de Janeiro: Paz e Terra, 1974.

OCDE. O ensino na sociedade moderna. Porto: ASA, 1989.

Papel da educação no desenvolvimento sócio-econômico. Lisboa: Ministério da Educação, 1987.

POULANTZAS, Nicos. Poder político y clases sociales en el Estado capitalista. México: Siglo XXI, 1970

1990.

Las clases sociales en el capitalismo actual. México: Siglo XXI,

MARTINS, António Maria. Formação e emprego numa sociedade em mutação. Aveiro: Universidade de Aveiro, 1999.

LOPES, H. Produção de competências no Portugal de amanhã: o desafio colocado às empresas portuguesas. In: Revista Portuguesa de Gestão, n 01, Lisboa, 1992.

OLIVEIRA, Manfredo Araújo. A nova problemática do trabalho e a ética". In: OLIVEIRA, Manfredo Araújo \& TEIXEIRA, Francisco J. S. (Orgs.). Neoliberalismo e reestruturação produtiva: as novas determinações do mundo do trabalho. São Paulo: Cortez; Fortaleza: Universidade Estadual do Ceará, 1996. 
PAIVA, Vanilda \& WARDE, Mirian. Novo paradigma do desenvolvimento e a centralidade do ensino básico. In: Educação \& Sociedade, n 14, São Paulo, 1993.

RIBEIRO, Maria Luísa S. A formação política do professor de $1^{\mathbf{0}}$ e $2^{\circ}$ graus. São Paulo: Cortez, 1984.

SCHULTZ, Theodoro. Capital humano. Rio de Janeiro: Zahar, 1973.

. O valor econômico da educação. Rio de Janeiro: Zahar, 1962.

UNESCO. Educação: um tesouro a descobrir. Porto: ASA, 1962.

. Educação, formação e emprego. Lisboa: Ministério da Educação, 1989.

\section{Notas}

${ }^{1}$ Universidade Federal da Paraíba (UFPB) - Campus do Litoral Norte; docente do Programa de Pósgraduação em Educação da Universidade do Estado do Rio Grande do Norte (UERN); Pesquisador-bolsista do CNPq; E-mail: ivonaldo.leite@gmail.com

${ }^{2}$ Entendendo-se, porém, que, em qualquer trabalho físico, "há actividade intelectual criadora" (Gramsci, 1978, p. 7)

${ }^{3}$ Sempre que referirmos o emprego é do trabalho abstracto (assalariado) que estamos a falar, como também sempre que tivermos em conta o trabalho em sentido assalariado é o emprego que estaremos a ter presente. Disto resulta, por exemplo, que se pode falar do mercado de trabalho como mercado de emprego.

${ }^{4}$ Que afirmam, por exemplo, ser fundamental desenhar e colocar em prática uma estratégia para impulsionar a transformação da educação e da formação na América Latina, objetivando que os países da região alcancem uma cidadania conjugada com equidade e competitividade, enfatizando-se que não se pode imaginar a cidadania "sem um esforço efetivo em matéria de competitividade" (CEPAL \& UNESCO, 1992, p. 18).

Recebido: Junho-2012

Aprovado: Setembro -2012 